\title{
Biochemical and functional changes in hearts from rabbits with diabetes
}

\author{
S. Bhimji ${ }^{1}$, D. V.Godin ${ }^{2}$ and J.H. McNeill ${ }^{1}$ \\ 'Division of Pharmacology and Toxicology, Faculty of Pharmaceutical Sciences and ${ }^{2}$ Department of Pharmacology and Therapeutics, \\ Faculty of Medicine, The University of British Columbia, Vancouver, B.C., Canada
}

\begin{abstract}
Summary. Biochemical and myocardial functional changes were determined in rabbits made diabetic with alloxan $(100 \mathrm{mg} / \mathrm{kg}$, intravenously, two injections $24 \mathrm{~h}$ apart). Alloxan-induced diabetes was characterized by a state of hypoinsulinaemia and hyperglycaemia. After 10 weeks of diabetes, significant decreases in heart and left ventricular weights as well as increased serum and heart triglycerides and cholesterol were observed in the diabetic animals $(p<0.05)$. In addition, left ventricular pressure, heart rate and rate of left ventricular pressure development were all decreased in the animals. The diabetic state was also associated with a slight elevation in myocardial calcium and a significant decrease in magnesium lev-
\end{abstract}

els $(p<0.05)$. Subcellular fractionation of diabetic hearts indicated the presence of alterations in myofibrillar and sarcoplasmic reticulum marker enzymes $(p<0.05)$. Among the lysosomal enzymes, measured, $\mathrm{N}$-acetyl $\beta$-glucosaminidase activity was significantly increased in the homogenates of diabetic left ventricles $(p<0.05)$. These alterations in hearts of diabetic rabbits may be responsible for some aspects of diabetic cardiomyopathy.

Key words: Alloxan-induced diabetes, myocardium, hyperglycaemia, calcium, magnesium, ATPase activity, lysosomal enzymes, diabetic cardiomyopathy, rabbit.
It is widely recognized that diabetic patients are more prone than the general population to cardiovascular disease, showing an increased incidence of myocardial infarction and heart failure [1]. Although diabetes has been repeatedly found to be associated with an increased mortality from vascular disease, there is mounting evidence to suggest that an abnormality of the myocardium may play a more important rôle than accelerated coronary atherosclerosis. To date, limited functional, structural and metabolic abnormalities have been demonstrated in the hearts of diabetic dogs [2] and rats [3].

The structural abnormalities include cardiac enlargement with scattered focal fibrosis, and an accumulation of periodic acid-Schiff staining material in the coronary arterial media and myocardium [2]. Functional studies suggest alterations in left ventricular diastolic compliance of hearts in diabetic dogs, and a slowing of relaxation and a depression of shortening velocity in left ventricular papillary muscles in diabetic rats [4]. In addition, studies in our laboratory have shown that diabetic rats have a depressed left ventricular function and exhibit signs of an autonomic neuropathy $[5,6]$.

To date, research on the cardiovascular complications of diabetes mellitus have been restricted by the lack of a suitable animal model. Although abnormalities of lipid and carbohydrate metabolism have been reported in a number of animal species [7], the pathogenesis is sufficiently different from that of human diabetes to restrict in depth studies on cardiovascular pathogenesis and treatment. For this reason, we have chosen to study cardiovascular complications in the diabetic rabbit, a species more prone to atherosclerosis than the rat. In the present study, we wish to characterize myocardial function in the absence of atherosclerosis. The course of the disease was followed by regular determinations of blood glucose, insulin and plasma lipids. In addition, chemical and biochemical parameters were studied on the hearts 10 weeks after the onset of diabetes and compared with control animals similar in age, weight and maintained on the same diet.

\section{Methods}

Adult male New Zealand white rabbits $(1.5-2.5 \mathrm{~kg})$ were fasted overnight before injection with alloxan. Alloxan monohydrate (Sigma Chemical Company, St. Louis, Mo.) was dissolved in sterile $\mathrm{NaCl}$ $(154 \mathrm{mmol} / 1)$ immediately before use and injected $(100 \mathrm{mg} / \mathrm{kg})$ into the caudal ear vein of lightly anaesthetized rabbits (sodium pentobarbital, $20 \mathrm{mg} / \mathrm{kg}$, intravenously). In some cases another injection was administered $24 \mathrm{~h}$ later. Because alloxan injection is irritating and painful, $0.5 \mathrm{ml}$ of $2 \%$ xylocaine was injected subcutaneously into the ear just before the injection of alloxan. Since alloxan is capable of producing fatal hypoglycaemia as the result of massive insulin release from the pancreas, animals were treated with $20 \%$ glucose $(15-20 \mathrm{ml})$ subcutaneously every $4-6 \mathrm{~h}$ for the first $24 \mathrm{~h}$ following alloxan administration. To prevent dehydration from the severe polyuria, intravenous $\mathrm{NaCl}(154 \mathrm{mmol} / 1,10 \mathrm{ml} / \mathrm{kg})$ was also administered. Rabbits which became diabetic after the first injection of alloxan were not giv- 
en a second dose. Control rabbits received intravenous saline $(0.85 \%)$ alone. Both the control and treated rabbits were caged separately and provided with food (Purina Rabbit Chow) and water ad libitum. The diabetic state was monitored by periodic tests for glycosuria using Tes-tape (Eli Lilly, Toronto, Canada) and ketones using ketostix (Eli Lilly, Toronto, Canada).

\section{Haemodynamic measurements}

After 10 weeks of diabetes, haemodynamic measurements were made in anaesthetized animals (sodium pentobarbital, $30 \mathrm{mg} / \mathrm{kg}$, intravenously). Catheters inserted into the carotid artery and directly into the left ventricle permitted monitoring of arterial and left ventricular pressure via two pressure transducers connected to a Grass Polygraph (Model 7PCP.8 Grass Instruments, Quincy, Mass.). The signal from the left ventricular pressure was fed into a calibrated Grass differentiator (Model 7P20C Grass Instruments, Quincy, Mass.). ECG were recorded continuously via subcutaneous electrodes.

\section{Tissue analyses}

Following completion of the haemodynamic measurements, hearts were excised and placed immediately in ice-cold $0.25 \mathrm{~mol} / 1$ sucrose. Homogenization and fractionation of the left ventricle to yield mitochondria and sarcolemma-enriched vesicle preparations were carried out as described by Godin et al. [8]. Membrane fractions were assayed for sarcolemmal $\mathrm{Na}^{+}-\mathrm{K}^{+}$-ATPase and $\mathrm{K}^{+}$-stimulated p-nitrophenylphosphatase, $\mathrm{K}^{+}-\mathrm{Ca}^{++}$-stimulated sarcoplasmic reticulum (azide-insensitive, EGTA inhibitable) ATPase and mitochondrial azide-sensitive ATPase. Myofibrillar ATPase was measured as described previously by Pierce and Dhalla [9]. To minimize the effects of vesiculation on measured enzyme activities, assays were performed in the presence of maximally activating concentrations of Triton X-100 $(0.005 \%$ for the mitochondrial fraction and $0.01 \%$ for the sarcolemmal fraction).

The lysosomal enzymes, cathepsin D, acid phosphatase and Nacetyl- $\beta$-glucosaminidase were determined in heart tissue according to the method of Godin et al. [8]. Myocardial sodium, potassium, magnesium and calcium levels were estimated by atomic absorption spectroscopy [10]. The water content was determined by drying samples to constant weight in an oven at $100{ }^{\circ} \mathrm{C}$. Hydroxyproline was measured in lipid-free dry tissue by the method of Woessner [11]. To analyze lipids in the heart, epicardial adipose tissue was trimmed and transmural samples were homogenized in phosphate buffer $(0.1 \mathrm{~mol} /$ $1, \mathrm{pH} 7.4)$ and the lipids extracted using a chloroform-methanol (2:1) mixture. Hearts for glycogen analyses were rapidly removed from the animal, blotted, digested and assayed according to the method of Seifter and Dayton [12].

\section{Serum analyses}

Blood samples were collected from fasted animals during the 10-week experimental period and centrifuged to separate plasma and erythrocytes. The plasma was assayed for total cholesterol [13], non-esterified fatty acids (NEFA) [14] triglycerides [15] and phospholipids [16]. The erythrocytes were used to measure glycosylation of haemoglobin [17].

Serum immunoreactive insulin levels were determined by a radioimmunoassay method employing human insulin as standard. The radioimmunoassay was performed using a commercial kit available from Becton, Dickinson and Company (Rutherford, New Jersey). Plasma glucose levels were monitored by the glucose-oxidase method using the Ames blood-glucose-analyzer reagent kit (Sigma Chemicals). Serum T3 and T4 levels were determined using a radioimmunoassay kit obtained from Amersham (Oakville, Ontario). Protein was determined by the method of Lowry et al. [18] using bovine serum albumin as a standard.

\section{Statistical analysis}

All the results were analyzed statistically using the Student's t-test for unpaired data with the level of significance set at $p<0.05$.

\section{Results}

With the model of alloxan-induced diabetes used, it was possible to produce diabetes for 10-12 weeks consistently in most of our rabbits. Overt diabetes ensued within 1-2 days after injection of alloxan, as manifested by increased food and water uptake and increased urine excretion associated with glycosuria.

Prior to analyzing the left ventricular function and biochemistry, the extent of atherosclerosis in the diabetic animals was investigated. Aortae from the diabetic animals showed some accumulation of cholesterol (control rabbits $10.2 \pm 2.1$, diabetic rabbits $16.4 \pm$ $3.2 \mathrm{mmol} / 100 \mathrm{~g}$ dry weight) and triglycerides (control rabbits $12.1 \pm 13.1$, diabetic rabbits $18.4 \pm 3.7 \mathrm{mmol} /$ $100 \mathrm{~g}$ dry weight) but the differences between the two groups of animals were not significant. In addition, sudan black staining and electron micrographs indicated that the aortae from diabetic animals did not appear to have any fatty streaks (unpublished observations).

\section{Body weight, food consumption and mortality}

The mean body weight of control and diabetic rabbits after 10 weeks was $3.8 \pm 0.3$ and $3.3 \pm 0.5 \mathrm{~kg}$, respectively. Food consumption was noticeably increased in diabetic animals, confirming the report of Martin and Hartroft [19], and in agreement with the results of a study of food intake in diabetic rats [20]. Polyuria and polydipsia were also observed in the diabetic rabbits.

Before the precautionary measures of glucose and saline administration were introduced, the mortality rate of the diabetic animals was about $60-80 \%$ within 24-48 $\mathrm{h}$ after alloxan treatment. Measurements of blood glucose of these animals suggested severe hypoglycaemia as the probable cause of death. After the administration of $20 \%$ glucose to counteract the hypoglycaemia, the mortality rate dropped to less than $10 \%$. In addition, some diabetic animals showed severe dehydration and died within one week after the onset of diabetes. Coincidentally, all of the rabbits that died had elevated serum triglyceride levels.

\section{Serum lipids and glucose}

The results of serum chemical analyses are summarized in Table 1. Total cholesterol, triglycerides, glucose and glycosylation of haemoglobin were significantly elevated in the diabetic animals $(p<0.05$, Table 1$)$. In contrast, there was a decrease in serum insulin after 10 weeks of diabetes. There was no change in either the circulating NEFA, serum phospholipid, T4 or T3 levels in diabetic or control animals.

\section{Left ventricular weight and water content}

The alloxan-treated rabbits had a decrease in both the heart and left ventricular weight compared with control rabbits (Table 1). Our recent observations indicate that 
Table 1. The effect of 10 weeks of diabetes on serum glucose, $T_{4}$, $\mathrm{T}_{3}$ insulin, lipids, body and heart weight

\begin{tabular}{|c|c|c|}
\hline & $\begin{array}{l}\text { Control rabbits } \\
(n=8)\end{array}$ & $\begin{array}{l}\text { Diabetic rabbits } \\
(n=8)\end{array}$ \\
\hline Glucose $(\mathrm{mmol} / 1)$ & $4.4 \pm 0.2$ & $23.3 \pm 0.6^{\mathrm{a}}$ \\
\hline Insulin $(\mathrm{mu} / \mathrm{l})$ & $23.2 \pm 2.3$ & $17.9 \pm 1.8^{\mathrm{a}}$ \\
\hline $\begin{array}{l}\text { Haemoglobin glycosylation } \\
\text { ( } \mu \text { mol HMF/g globin })\end{array}$ & $1.2 \pm 0.4$ & $4.7 \pm 0.9^{\mathrm{a}}$ \\
\hline Cholesterol $(\mathrm{mmol} / \mathrm{l})$ & $2.1 \pm 0.3$ & $5.2 \pm 0.4^{\mathrm{a}}$ \\
\hline Phospholipid (mmol/l) & $0.14 \pm 0.04$ & $0.12 \pm 0.04$ \\
\hline $\mathrm{NEFA}(\mathrm{mmol} / \mathrm{l})$ & $1.1 \pm 0.2$ & $1.7 \pm 0.3$ \\
\hline Triglycerides (mmol/1) & $0.79 \pm 0.04$ & $1.5 \pm 0.1^{\mathrm{a}}$ \\
\hline Body weight (kg) & $3.8 \pm 0.3$ & $3.3 \pm 0.5$ \\
\hline Heart weight $(\mathrm{g})$ & $5.5 \pm 0.6$ & $3.8 \pm 0.6^{\mathrm{a}}$ \\
\hline Left ventricular weight ( $\mathrm{g}$ ) & $3.9 \pm 0.7$ & $2.4 \pm 0.6^{\mathrm{a}}$ \\
\hline$\frac{\text { Heart weight }}{\text { Body weight }}(\mathrm{g} / \mathrm{kg})$ & $1.4 \pm 0.2$ & $1.1 \pm 0.1$ \\
\hline Dry heart weight $(\mathrm{mg} / \mathrm{g})$ & $227 \pm 18$ & $242 \pm 12$ \\
\hline $\begin{array}{l}\text { Heart water content } \\
\text { ( } \% \text { wet weight })\end{array}$ & $77.6 \pm 0.3$ & $78.2 \pm 0.7$ \\
\hline $\mathrm{T}_{4}(\mu \mathrm{g} / 100 \mathrm{ml})$ & $4.0 \pm 0.2$ & $3.6 \pm 0.5$ \\
\hline $\mathrm{T}_{3}(\mathrm{ng} / 100 \mathrm{ml})$ & $7.1 \pm 1.0$ & $6.9 \pm 0.7$ \\
\hline
\end{tabular}

Results expressed as mean \pm SEM. ${ }^{a} p<0.05$, significant difference from control value. ${ }^{b}$ Glycosylation of haemoglobin was measured as $\mu \mathrm{mol}$ hydroxymethyl furfural/g globin

Table 2. The effect of 10 weeks of diabetes on various cardiovascular parameters

\begin{tabular}{lcr}
\hline & $\begin{array}{l}\text { Control rabbits } \\
(n=8)\end{array}$ & $\begin{array}{l}\text { Diabetic rabbits } \\
(n=8)\end{array}$ \\
\hline $\begin{array}{l}\text { Left ventricular pressure } \\
\text { (mmHg) }\end{array}$ & $125 \pm 10$ & $100 \pm 5^{\mathrm{a}}$ \\
$\begin{array}{l}\text { Positive rate of left } \\
\text { ventricular pressure } \\
\text { development (mmHg/s) }\end{array}$ & $4000 \pm 360$ & $3200 \pm 220^{\mathrm{a}}$ \\
Blood pressure (mmHg) & & \\
$\quad$ Systolic: & $120 \pm 10$ & $115 \pm 10$ \\
$\quad$ Diastolic: & $85 \pm 5$ & $85 \pm \quad 5$ \\
Heart rate (beats/min) & $300 \pm 20$ & $260 \pm 15^{\mathrm{a}}$ \\
Left ventricular end & $5 \pm 2$ & $8 \pm 4$ \\
$\quad$ diastolic pressure (mmHg) & & \\
\hline
\end{tabular}

Results are expressed as mean \pm SEM. ECG recordings did not reveal any significant cardiac alterations in diabetic animals. ${ }^{\mathrm{a}} p<0.05$, significant difference from control value

Table 3. The effect of 10 weeks of diabetes on left ventricular content of ions and biochemical substances

\begin{tabular}{lcc}
\hline & $\begin{array}{c}\text { Control rabbits } \\
(n=8)\end{array}$ & $\begin{array}{l}\text { Diabetic rabbits } \\
(n=8)\end{array}$ \\
\hline $\mathrm{Na}^{+}$(nmol/mg dry weight) & $29.2 \pm 11.1$ & $37.6 \pm 6.6$ \\
$\mathrm{~K}^{+}$(nmol/mg dry weight) & $292 \pm 13$ & $268 \pm 21$ \\
$\mathrm{Mg}^{2+}$ (nmol/mg dry weight) & $28.7 \pm 2.3$ & $22.6 \pm 1.7^{\mathrm{a}}$ \\
$\mathrm{Ca}^{2+}$ (nmol/mg dry weight) & $5.3 \pm 0.9$ & $6.7 \pm 0.6$ \\
$\mathrm{Cholesterol}(\mathrm{mg} / \mathrm{g})_{\text {Triglyceride (mg/g) }}^{3.1 \pm 0.8}$ & $5.9 \pm 0.6^{\mathrm{a}}$ \\
Hydroxyproline & $12.7 \pm 1.9$ & $36.8 \pm 3.9^{\mathrm{a}}$ \\
$\quad(\mu \mathrm{g} / \mathrm{mg}$ dry weight) & $3.2 \pm 0.4$ & $5.0 \pm 0.3^{\mathrm{a}}$ \\
Glycogen (mg/g) & $5.2 \pm 0.8$ & $8.7 \pm 0.9^{\mathrm{a}}$ \\
Phospholipid $(\mathrm{mg} / \mathrm{g})$ & $6.6 \pm 1.1$ & $6.9 \pm 0.9$ \\
\hline
\end{tabular}

Results expressed as mean \pm SEM. ${ }^{a} p<0.05$ significant difference from control value there are two subtypes of diabetic conditions produced by alloxan in the rabbit, i.e., one with just hyperglycaemia and the other with hyperglycaemia and hyperlipidaemia. All rabbits with hyperglycaemia and hyperlipidaemia showed not only significant decreases in body weight, but also decreases in the heart and left ventricular weights. Since we were not aware of this phenomenon earlier, the present study has included data from both groups of animals. The wet heart weight to body weight ratio was not significantly altered in diabetic animals. No changes were observed in either the mean dry weight or the total water content of hearts of diabetic compared to control animals.

\section{Haemodynamic measurements}

The effects of alloxan-induced diabetes on haemodynamic properties are shown in Table 2. After the development of steady-state anaesthesia, haemodynamic studies revealed that left ventricular pressure, heart rate and the rate of positive left ventricular pressure development were significantly reduced in diabetic animals $(p<0.05$, Table 3$)$. ECG recordings from chest and limb electrodes did not reveal any significant cardiac alterations in diabetic animals (data not shown).

\section{Myocardial composition}

Analyses of left ventricles from control and diabetic animals are shown in Table 3 . Tissue levels of $\mathrm{Na}^{+}$and $\mathrm{K}^{+}$in diabetic left ventricles showed no differences relative to control. However, significant reduction in tissue $\mathrm{Mg}^{2+}(p<0.05$, Table 3) and a slight but insignificant accumulation of $\mathrm{Ca}^{2+}$ was observed in left ventricles of diabetic animals. We have also shown that $\mathrm{Ca}^{2+}$ accumulation also occurs in the arteries and aortae of diabetic animals (unpublished observations). Further analyses of left ventricles from diabetic animals revealed extensive accumulation of cholesterol, triglyceride, hydroxyproline and glycogen with no change in phospholipid levels. Of the various ATPases studied in left ventricles from diabetic animals, both myofibrillar and sarcoplasmic reticulum, $\mathrm{K}^{+}, \mathrm{Ca}^{2+}$-stimulated (EGTA inhibited) ATPases showed significant reductions $(p<-$ 0.05 , Fig. 1). Mitochondrial azide-sensitive ATPase, sarcolemmal $\mathrm{Na}^{+}, \mathrm{K}^{+}$-stimulated (ouabain-sensitive) ATPase and $\mathrm{K}^{+}$-stimulated p-nitrophenylphosphatase were not significantly decreased in the left ventricles of diabetic compared to control rabbits.

\section{Lysosomal enzymes}

The effects of diabetes on left ventricular lysosomal enzymes are shown in Figure 2. Analyses of myocardial homogenates from diabetic animals revealed a small, but significant reduction in the particulate (sedimentable) fraction of $\mathrm{N}$-acetyl- $\beta$-glucosaminidase activity $(p<0.05$, Fig. 2). In contrast, acid phosphatase, a less specific marker for myocardial lysosomal structures 

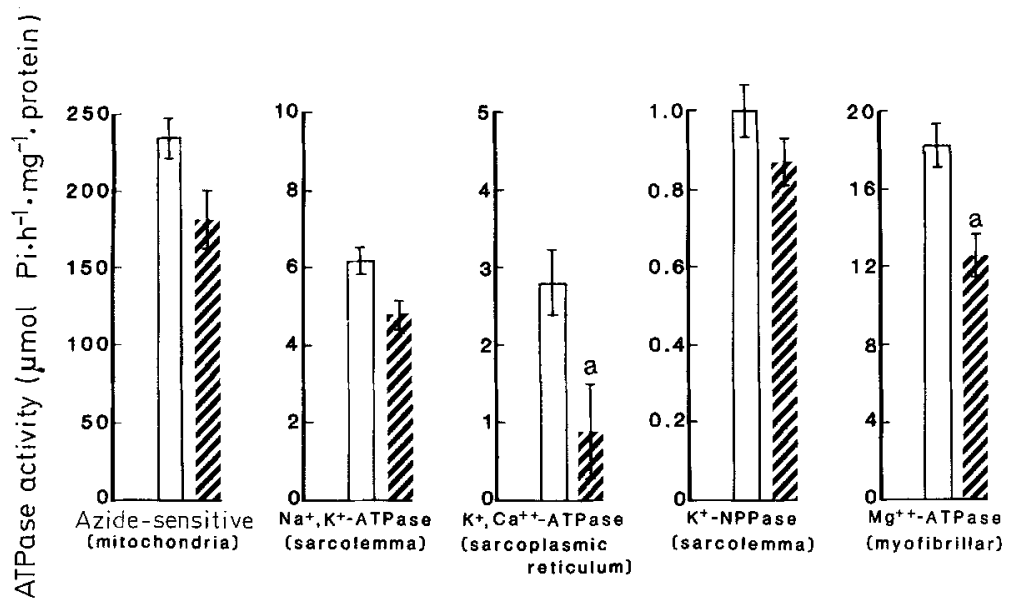

Fig. 1. Mitochondrial, sarcolemmal, sarcoplasmic reticulum and myofibrillar ATPase activities in the left ventricles of control ( $\square$ ) and diabetic ( $\square$ ) rabbits. Results expressed as mean $\pm \operatorname{SEM}\left(n=8\right.$ animals). ${ }^{a} p<0.05$. Significant difference from control value

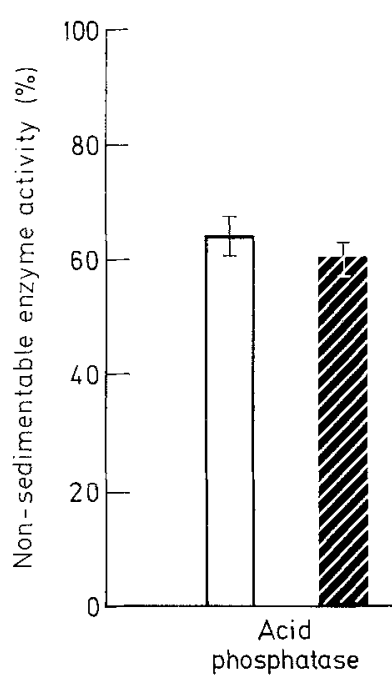

than $\mathrm{N}$-acetyl $-\beta$-glucosaminidase, did not show any significant changes in sedimentation characteristics following alloxan treatment. Cathepsin $\mathrm{D}$, another specific lysosomal enzyme, did not show any significant difference in activity compared with control.

\section{Discussion}

One of the major problems in attempting to study the nature of cardiovascular complications in diabetes relates to the multiplicity of levels of structural and functional organization at which alterations may be investigated. Because it is clear that chemical, biochemical and functional abnormalities are closely interrelated, and because of the difficulty in comparing results from different species, we have explored some of these diverse aspects of myocardial changes in a diabetic rabbit model in order to gain a better understanding of events leading to experimental diabetic cardiomyopathy.

The present experimental protocol reliably produced a diabetic state characterized by hypoinsulinaemia and hyperglycaemia which persisted throughout the study. Unlike the report of Lazarus and Shapiro [21], we were unable to induce diabetes in rabbits with streptozotocin $(150-300 \mathrm{mg} / \mathrm{kg})$, suggesting that rabbits are resistant to streptozotocin and thus confirming the report of Kushner et al. [22]. The changes observed in the hearts of diabetic animals are definitely due to the catabolic changes induced by alloxan. Some rabbits injected with alloxan did not turn out to be diabetic, and since the hearts of these animals did not show any biochemical or functional alterations, it further suggests that alloxan does not have a direct effect on the heart. The biochemical and functional changes were studied after 10-12 weeks since our preliminary time-course studies revealed that no significant alterations were present prior to this time period [23].

Because of the limited quantity of tissue available from the atria, the biochemical studies were limited to the left ventricles. One of the most distinct changes observed in the diabetic rabbits as compared to the diabetic rats was the lack of any thyroid hormone depression. Thyroid hormone depression in diabetic rats has been reported by numerous laboratories [24]. The failure to see any thyroid hormone depression in the diabetic rabbit is not yet understood, but could perhaps be dependent upon the severity and duration of the diabetic state.

In our study we observed that hyperglycaemia alone did not significantly affect body weight of the diabetic animals. However, hyperglycaemia in the presence of 
hyperlipidemia significantly decreased not only the body weight, but also the heart and left ventricular weights of the diabetic animals. Recent studies in our laboratory have shown that diabetic rats treated with lipid lowering drugs show no drastic alterations in heart weight or heart function [25].

Of the various subcellular organelle-specific ATPases examined, we found a depression only in the myofibrillar and sarcoplasmic reticular $\mathrm{K}^{+}, \mathrm{Ca}^{++}$-stimulated ATPase. The inhibition of the latter is consistent with the studies of Lopaschuk et al. [26] who also showed an impairment of the ability of cardiac sarcoplasmic reticulum to accumulate calcium in streptozotocin-induced diabetic rats. Studies by Dillman [27] indicate that the depression of myofibrillar ATPase is due to an alteration in the composition of myosin isoenzymes. This defective utilization of ATP by the myofibrils may contribute to the depression of contractile function in hearts of diabetic animals. Barany [28] has observed a close relationship between ATPase activity and contractile function of skeletal muscle, and numerous other studies suggest a similar parallel relationship between contractile function and protein ATPase [29].

Membrane bound sarcolemmal $\mathrm{Na}^{+}, \mathrm{K}^{+}$-stimulated ATPase and $\mathrm{K}^{+}$-stimulated p-nitrophenylphosphatase were not significantly altered in diabetic rabbits and the normal myocardial contents of water, $\mathrm{Na}^{+}$and $\mathrm{K}^{+}$further support the idea that, unlike the situation in ischaemic injury, sarcolemmal integrity was largely preserved. However, a recent study by Regan et al. [2] in diabetic dogs demonstrated changes in tissue sodium and increases in water content. However, these alterations have been attributed to an elevation in interstitial glycoprotein anionic binding sites rather than to a change in sarcolemmal membrane permeability.

We also observed an increase in the hydroxyproline concentration in hearts of diabetics. The increase in hydroxyproline concentration in the myocardium in diabetes usually indicates increased collagen synthesis. The basis for the collagen increment in the absence of hypertrophy in diabetes has not been well examined. Regan et al. [2] suggest that degradation of collagen is diminished, since insoluble collagen was increased in heart muscle, while the acid-soluble fraction declined. It could also be that collagen deposition might occur as the result of tissue injury. Whatever the reason, the increase in myocardial stiffness in diabetic patients has been ascribed to compositional changes in the fibrous protein [2].

Total ion measurements demonstrated calcium accumulation and magnesium depletion in left ventricles of diabetic animals. Our recent studies indicate that the magnesium depletion in the diabetic rabbits is not only limited to the left ventricle, but is also found in the right ventricle, aorta, skeletal muscle and red blood cells. It appears that the magnesium depletion in the red blood cells is dependent upon the blood glucose levels (unpublished observations).
As yet, the importance of an alteration in calcium/ magnesium ratio in left ventricles of diabetic animals has not been definitely established. However, clinical data indicate that diabetic patients are more prone to medial arterial calcification which increases with age and duration of diabetes [30]. The aetiology and pathogenesis of this type of calcification in diabetes is as yet unknown. Decreased levels of serum $\mathrm{Mg}^{2+}$ have until recently been a poorly recognized feature of diabetes [31]. Although its origin is unknown, it seems to be associated with poor diabetic control. It has been proposed that hypomagnesaemia might be a risk factor in the development of diabetic retinopathy, and a case for $\mathrm{Mg}^{2+}$ supplements has been put forward as a possible means of reducing vascular complications of diabetes [32].

Changes in total activity of lysosomal enzymes and the morphology of cardiac lysosomes have been found to accompany pathological changes in the heart. One of the earliest described biochemical manifestations of tissue damage is a decreased sedimentability of lysosomal hydrolases [33]. It is generally unclear whether these are a cause or a consequence of injury. A qualitatively similar effect suggestive of decreased lysosomal stability either in vivo or during homogenization in vitro has been seen in our diabetic rabbits. Similar studies by Chua et al. [34] have shown that alterations in cardiac lysosomal enzymes are associated with accelerated rates of proteolysis in working hearts of diabetic animals.

Our findings indicating the presence of impaired contractile function in the hearts of diabetic animals parallel the results of studies using isolated perfused hearts. Recently, a number of clinical and experimental studies have been published in which cardiac function in diabetes has been studied. Frequent abnormalities of left ventricular function attributed to a "preclinical cardiomyopathy" have been detected by haemodynamic and non-invasive methods in diabetic patients without clinical evidence of heart disease [35]. Histological and necropsy reports are, however, conflicting on the presence, extent and significance of atherosclerosis and diabetic microvascular involvement of the coronary circulation in the above patients [36].

The molecular basis of the depression of left ventricular function in experimental diabetes has not yet been definitely established. Work by Lopaschuk et al indicates that the elevated levels of long chain acylcarnitines in the sarcoplasmic reticulum of hearts of diabetic rats are likely to play a role in this regard [37]. The depression of myosin ATPase may also be involved [9, 28].

The heart normally derives most of its energy for contraction from NEFA. The accumulation of triglyceride in left ventricles of diabetic animals may reflect lipase inhibition, resulting in a diminished supply of NEFA and impaired contractile function of the diabetic myocardium [38]. Scar formation and diffuse fibrosis could also impair left ventricular function. In addition, blood viscosity, platelet adhesion and erythrocyte deformability are also abnormal in diabetes; these rheo- 
logical disturbances may reduce local tissue perfusion and further compromise the coronary circulation in vivo [39]. A spectrum of abnormalities of left ventricular function exists in diabetes ranging from normal to severely depressed contractile function. Whether they are a result of one disorder with a common aetiology or of unrelated disorders with differing pathogenesis is unknown, though it seems likely that they are multifactorial.

The above biochemical and functional analyses indicate that several alterations take place in hearts of 10 -week diabetic rabbits. Clearly, there is a need to further explore the details of the relationship between diabetes and cardiovascular disease.

Acknowledgements. This study was supported by grants from the British Columbia Heart Foundation and the British Columbia Branch, Canadian Diabetes Association.

\section{References}

1. Ledet T, Neubauer B, Christensen N, Lundback K (1979) Diabetic cardiomyopathy. Diabetologia 16: 207-209

2. Regan TJ, Wu FC, Yeh KC, Oldewurtel AH, Haider B (1981) Myocardial composition and function in diabetes. Circ Res 49: $1268-1277$

3. Fein FS, Kornstein IB, Strobeck JE, Capasso JM, Sonnenblick E (1980) Altered myocardial mechanics in diabetic rats. Circ Res 47: 922-933

4. Dhalla NS (1973) Myocardial metabolism. In: Vol III Recent advances in studies on cardiac structure and metabolism. (ed) Dhalla N. University Park, Baltimore, pp 169-179

5. Vadlamudi RVSV, McNeill JH (1983) Effect of alloxan and streptozotocin-induced diabetes on isolated rat heart responsiveness to carbachol. J Pharmacol Exp Ther 225: 410-415

6. Vadlamudi RVSV, Rodger RL, McNeill JH (1982) The effect of chronic alloxan- and streptozotocin-induced diabetes on isolated rat heart performance. Can J Physiol Pharmacol 60:902-911

7. Denton RM, Randle RJ (1967) Concentration of glycerides and phospholipids in rat heart and gastrocnemius muscles. Effects of alloxan-diabetes and perfusion. Biochem J 104: 416-422

8. Godin DV, Tuchek J, Moore M (1980) Membrane alterations in acute myocardial ischemia. Can J Biochem 58: 777-786

9. Pierce GN, Dhalla NS (1981) Cardiac myofibrillar ATPase activity in diabetic rats. J Mol Cell Cardiol 13:1-6

10. James MK, Roufogalis BD (1977) The effects of ouabain on the guinea pig ileum longitudinal smooth muscle ATPase activities in a sarcolemma enriched fraction prepared with the aid of divalent cation-depletion of the intact muscle. Can J Physiol Pharmacol 21: $1190-1196$

11. Woessner JF (1961) Determination of hydroxyproline in tissue and protein samples containing small proportion of this imino acid. Arch Biochem Biophys 93: 440-447

12. Seifter S, Dayton S (1949) Estimation of glycogen with the anthrone reagent. Fed Proc 8: 249-256

13. Levine JA, Zak B (1964) Automated determination of serum total cholesterol. Clin Chim Acta 10:381-384

14. Kelly TF (1975) Improved method for micro determination of fatty acids. Anal Chem 47: 1078-1079

15. Kaplan A, Lee AF (1965) Micro method for determination of serum triglycerides. Proc Soc Expt Biol Med 118: 296-300

16. Bartlett $G$ (1979) Bartlett variation of Fiske-Subbarow phosphorous method. J Biol Chem 234: 466-469

17. Subramanian CV, Radkrishnamurthy R, Berenson GS (1980) Photometric determination of glycosylation of hemoglobin in diabetes mellitus. Clin Chim 26: 1683-1687
18. Lowry OH, Rosebrough NJ, Farr AL, Randall RJ (1951) Protein measurement with the folin phenol reagent. J Biol Chem 193: 265-275

19. Martin JM, Hartroft WS (1965) Atherogenecity of saturated or unsaturated dietary fats in pancreatectomized rats. In: The nature and treatment of diabetes mellitus. Proc 5th Cong Int Diab Fed (eds) Leibel BS and Wrenshall GA. Excerpta Medica Foundation Amsterdam, pp 410-428

20. Kurnaresan P, Turner CW (1965) Effects of alloxan on food consumption in rats. Proc Soc Expt Biol Med 119: 400-406

21. Lazarus S, Shapiro S (1972) Streptozotocin-induced diabetes and islet cell alterations in rabbits. Diabetes 21:129-137

22. Kushner B, Lazar M, Furman M, Liebeman T, Leopold I (1969) Resistance of rabbits and guinca pigs to the diabetogenic effects of streptozotocin. Diabetes 18: 542-546

23. Bhimji S, Godin DV, McNeill JH (1985) Ultrastructural alterations in alloxan-induced rabbit hearts. Acta Anat (Basel) (in press)

24. Tahiliani AG, McNeill JH (1984) Lack of effect of thyroid hormone on diabetic rat heart function and biochemistry. Can J Physiol Pharmacol 62: 617-621

25. McNeill JH, Rodrigues B (1985) Hydralazine reverses bradycardia, hypertension and elevated serum lipids in STZ diabetic rats. Fed Proc 44: 1658 (Abstract)

26. Lopaschuk G, Katz S, McNeill JH (1983) The effects of alloxaninduced diabetes on $\mathrm{Ca}$ transport in cardiac sarcoplasmic reticulum. The possible involvement of long chain acylcarnitine. Can J Physiol Pharmacol 61: 439-448

27. Dillman WH (1980) Diabetes mellitus induces changes in cardiac myosin of the rat. Diabetes 29: 579-582

28. Barany M (1967) ATPase activity of myosin correlated with speed of muscle shortening. J Gen Physiol 50: 197-218

29. Garber DW, Neely JR (1983) Decreased myocardial function and myosin ATPase in hearts from diabetic rats. Am J Physiol 244: H586-H591

30. Goebel FD, Fuessl HS (1983) Monckeberg's sclerosis after sympathetic denervation in diabetic and non-diabetic subjects. Diabetologia 24: $347-350$

31. Levin GE, Mather HM, Pilkington TC (1981) Tissue magnesium status in diabetes mellitus. Diabetologia 21: 131-134

32. Anonymous (1979) Hypomagnesaemia and diabetic retinopathy. Lancet 1: $762-766$

33. DeDuve $\mathrm{CH}$, Beaufoy $\mathrm{H}$ (1959) Influence of ischemia on the state of some bound enzymes in rat liver. Biochem J 73:610-616

34. Chua B, Long W, Lautensack N, Lins J, Morgan H (1983) Effect of diabetes on cardiac lysosomes on protein degradation. Am J Physiol 245: C91-100

35. Penpargkul S, Fein F, Sonnenblick E, Scheuer J (1981) Depressed cardiac sarcoplasmic reticulum function in diabetic rats. J Mol Cell Cardiol 13: 1303-1309

36. Ahmed SS, Jeferi GA, Narang RM, Regan TJ (1975) Preclinical abnormality of left ventricular function in diabetes mellitus. Am Heart J 89: 153-158

37. Lopaschuk GD, Tahiliani A, Vadlamudi RVSV, Katz S, McNeill JH (1983) Cardiac sarcoplasmic reticulum function in insulin- or carnitine-treated diabetic rats. Am J Physiol 245: H969-976

38. Paulson DJ, Crass MF (1982) Exogenous triacylglycerol metabolism in diabetic heart. Am J Physiol 242: H1084-1094

39. Fuller JH, Keen M, Jarett RJ (1979) Haemostatic variables associated with diabetes and its complications. $\mathrm{Br}$ Med $\mathbf{J}$ 11: 1946-1949

Received: 16 October 1984

and in revised form: 8 June 1985

Dr. J.McNeill

Pharmaceutical Sciences

The University of British Columbia

Vancouver, V6T 1W5, Canada 